\title{
Preparation and characterization of polyacrylate functionalized polythiophene films
}

\author{
Yahui $\mathrm{Lv}^{1,2}$, Fei $\mathrm{Wu}^{3}$, Chengshuai $\mathrm{Liu}^{3}$, Changzhong $\mathrm{Liao}^{2}$, Yingheng Fei ${ }^{4, \mathrm{a}}$, Menghua Chen² and Meifang Hou ${ }^{1, \mathrm{a}}$ \\ ${ }^{1}$ Shanghai Institute of Technology, Shanghai 201418, P. R. China \\ ${ }^{2}$ Guangdong Key Laboratory of Integrated Agro-environmental Pollution Control and Management, Guangdong Institute of Eco- \\ environmental Science \& Technology, Guangzhou 510650, P. R. China \\ ${ }^{3}$ State Key Laboratory of Environmental Geochemistry, Institute of Geochemistry, Chinese Academy of Sciences, Guiyang 550009, P. R. \\ China \\ ${ }^{4}$ School of Environmental Science and Engineering, Guangzhou University, Guangzhou 510006, P. R. China
}

\begin{abstract}
This paper is based on the effect of precursors' structure on the resultant electropolymers' electrochemical and optical and thermal properties. The polyacrylate functionalized thiophene with a narrow polydispersity index (PDI) was synthesized by means of reversible addition-fragmentation chain transfer (RAFT) polymerization, and then the free-standing and conducting conjugated polyacrylate functionalized polythiophene (R-PTE-PAA) film was prepared through electropolymerization in $\mathrm{CH}_{2} \mathrm{Cl}_{2}$ with 50\% BFEE (boron trifluoride diethyl etherate). For comparison, the polyacrylate functionalized polythiophene (PTE-PAA) was also prepared with the precursor of a broad PDI from conventional free radical polymerization. The prepared polymers were characterized by UV-vis, FT-IR spectroscopy, thermogravimetry, cyclic voltammetry, scanning electron microscopy and fluorescence spectrophotometry. The R-PTE-PAA film showed the excellent electrochemical behavior, good blue-light property and high thermal stability. Compared with PTE-PAA, the R-PTE-PAA film presented the better electrochemical reversibility and stability. The results obtained in the present study indicate that the R-PTE-PAA film would be important for applications in electrochromics, supercapacitors and electrochemical sensors.
\end{abstract}

\section{Introduction}

Polythiophene (PTh) as well as its derivatives are a group of universally studied conducting polymers because of its low cost, light weight, good electrochromic behavior, high electrical conductivity and stability[1-3], and thus their applications attracted much attention in organic electronics and optoelectronics, such as organic electroluminescent diodes (OLED), thin-film organic field effect transistors (OFET), organic photovoltaic devices (OPV) $[4,5]$ and so on. However, the difficulties in processing and film-forming of PTh and its derivatives limit their wide applications. Therefore, a large number of researches and scientists are interested in devoting tremendous efforts to build the promising and potential PTh materials [6-9].

As (meth)acrylic resins present good film-forming properties, good mechanical properties[10], long open times, good chemical resistance as well as consistent clarity (nonyellowing)[11], some precursors containing both aromatic electroactive units and poly(meth)acrylate moieties have been developed[12, 13]. For example, (meth)acrylate functionalized thiophene, pyrrole[14-17], fluorine[18], carbazole[19, 20] or 3,4ethylenedioxythiophene (EDOT)[2] have been synthesized, which were polymerized into poly(meth)acrylate with pendant aromatic ring units through free radical polymerization method and then transformed into conducting poly(meth)acrylate modified polymers by the secondary electrochemical polymerization on the pendant aromatic units. These resultant polymers are expected to be used for designing and fabricating potential devices[17].

It is usually considered that many properties of polymers are seriously dependent on the polydispersity index (PDI) of the polymers [21]. Generally, the precursors obtained by conventional free radical polymerization have a broad PDI, which possibly affect the electrochemical behaviors and other properties of the resultant polymers. Hence, it is meaningful and reasonable to synthesize precursors with narrow PDI and investigate the properties of such precursors and their resultant polymers.

As a novel and promising method, compared with the free radical polymerization method, living/controlled radical polymerization (LRP) can exactly control and adjust the polymer chain microstructures incorporating molecular weight and its distribution and composition distribution, etc. [22]. There are several prevailing techniques in the group of LRP, including nitroxidemediated polymerization (NMP)[23], atom transfer radical polymerization (ATRP)[24] and reversible 
addition-fragmentation chain transfer (RAFT)[25-27] polymerization. Among them, the RAFT process reported by Rizzardo et al. is one of the promising ones[28, 29], which could be enforced in a broad extent of solvents (including water) and applicable to a wide scope of monomers under a wide range of experimental conditions.[28] Besides, a variety of functional polymers and macromolecules with special architectures including block[30, 31], star[32, 33], graft[34, 35], telechelic[36], hyperbranched structures and supermolecular assemblies[37] are accessible. More importantly, the RAFT process could also be used to study well-explicit macromolecular architectures with a wide scope of functional monomers[29]. Therefore, in this paper, RAFT method was chosen to synthesize a precursor from the functional monomer 3-ethyl acrylate-thiophene with narrow PDI. The precursor was further prepared into a free-standing conducting polymer by the secondary electropolymerization on the pendant thiophene units in a mixed solution containing 50\% (vol) BFEE and 50\% (vol) $\mathrm{CH}_{2} \mathrm{Cl}_{2}$. Excessively and significatively, we detailly study and analysis the thermal stability, light-emitting properties and electrochemical behavior of the resultant polymer along with its film.

\section{Materials and Methods}

\subsection{Materials}

3-Ethyl acrylate-thiophene (TE-AA)[8] and RAFT agent 3-benzylsulfanyl- thiocarbonylsufanylpropionic acid[38] were synthesized according to the reported method. Azodiisobutyronitrile (AIBN) and 4,4'-azobis(4cyanovaleric acid) (ACVA) were purchased from Aladdin Industrial Corporation (China). Boron trifluoride diethyl etherate (BFEE) was bought from Beijing Xin'ao Xunchi Chemicals Co. Ltd., China and used after vacuum distillation. Dichloromethane (DCM), tetrahydrofuran (THF), dioxane and methyl methacrylate (MMA) were all analytical grade chemicals and obtained from Beijing Chemical Works (China) and used after reflux distillation.

\subsection{Conventional radical polymerization of TE- AA}

A $250 \mathrm{~mL}$ round-bottom flask containing TE-AA $(6.2 \mathrm{~g}$, $34 \mathrm{mmol})$, AIBN (0.056 g, $0.34 \mathrm{mmol})$ and $120 \mathrm{~mL}$ of THF was sealed under a nitrogen atmosphere and polymerization occurred under $333 \mathrm{~K}$. After maintained at $333 \mathrm{~K}$ for $2 \mathrm{~d}$, the solvent was concentrated. Firstly, the raw product was precipitated in methanol and subsequently re-dissolved in methylene chloride. After re-precipitation in methanol and drying, the raw polymer was obtained as a ropy claybank dope, which was then dissolved in chromatographically pure THF for size exclusion chromatography analysis (against poly(methyl methacrylate) standards): $\quad \mathrm{Mn}=2902, \quad \mathrm{Mw}=4593$, $\mathrm{Mw} / \mathrm{Mn}=1.58$. The obtained polymer was defined as TEPAA.

\subsection{RAFT polymerization of TE-AA}

In the experiment, a round-bottomed flask was charged with $32 \mathrm{mmol}$ TE-AA, $0.16 \mathrm{mmol}$ ACVA and $1.6 \mathrm{mmol}$ RAFT agent in dioxane, followed by deoxygenating by argon bubbling for $30 \mathrm{~min}$ at room temperature and was then immersed in a preheated oil bath thermostatted at $403 \mathrm{~K}$. The reaction was terminated after $2 \mathrm{~d}$ by cooling the reaction flask in an ice bath followed by exposure to air. After the solvent was concentrated, the polymer was first precipitated in methanol, and then re-dissolved in methylene chloride. After re-precipitation in methanol and complete drying, the raw polymer obtained as a ropy claybank dope was dissolved in chromatographically pure THF for size exclusion chromatography analysis (against poly(methyl methacrylate) standards): $M n=3095$, $\mathrm{Mw}=4581, \mathrm{Mw} / \mathrm{Mn}=1.48$. The obtained polymer was defined as R-TE-PAA.

\subsection{Electropolymerization of R-TE-PAA and TE- PAA}

As shown in Figure 1, under the help of a potentiostatgalvanostat (model 263, EG\&G Princeton Applied Research) controlled by computer, electrochemical polymerization of the two precursors were performed successfully in a one-compartment cell. Beyond that, during the electrochemical tests, the two Pt wires with a diameter of $1 \mathrm{~mm}$ as working and counter electrodes respectively were placed $1 \mathrm{~cm}$ apart. More importantly, we used ITO $(2 \mathrm{~cm} \times 2 \mathrm{~cm})$ as the working electrode to get a large of the polymer films for characterization. Before each experiment, these electrodes were need to clean carefully with ethanol and then dried in air. An $\mathrm{Ag} / \mathrm{AgCl}$ electrode as the reference electrode showed great stability during the experiments. The typical electrolytic solution was 50\% (vol) BFEE and 50\% (vol) $\mathrm{CH} 2 \mathrm{Cl} 2$ containing $6.5 \mathrm{mmol} / \mathrm{L}$ precursor (R-TE-PAA or TE-PAA). All solutions were deaerated by a dry nitrogen stream and maintained under a slight overpressure through all the experiments. It is convenient and easy to adjust the amount of polymer deposited on the electrode by changing the integrated charge passed through the cell, which could be presented directly from the current-time (I-t) curves through a computer. The resultant electropolymerized films were immersed in acetone and water to clean up the electrolyte and oligomer/monomer. Also, the polymer films were dedoped with $25 \%$ ammonia for $3 \mathrm{~d}$ for spectral analyses, and then washed with pure water for several times. Finally, under vacuum the polymer films were dried at $333 \mathrm{~K}$ for $24 \mathrm{~h}$.

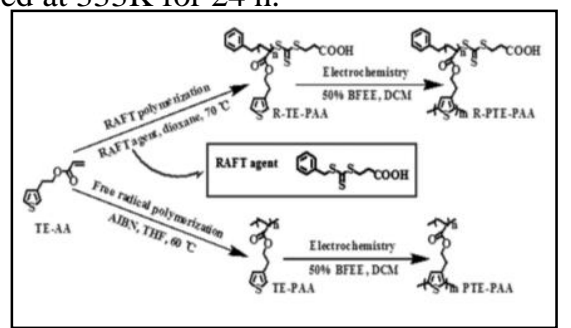

Figure 1. Synthesis routes of R-TE-PAA and TE-PAA and their electrochemical polymerization. 


\subsection{Characterization}

Infrared spectra were recorded using a Bruker Vertex 70 Fourier transform infrared (FT-IR) spectrometer (Bruker, Germany) with precursors in $\mathrm{KBr}$ pellets. The IR characterizations of the resultant crosslinked polymers were performed by attenuated total reflectance (ATRFTIR). The UV-vis spectra were detected with Agilent 8453 spectrometer (Agilent, Australia). The fluorescence spectra were determined with an F-4500 fluorescence spectrophotometer (Hitachi, Japan). Gel permeation chromatographys (GPC) (PMMA as interior label) measurements of the samples were performed in high purity solvent THF with a Waters Breeze GPC system (Waters, USA). Thermogravimetric analysis (TGA) and differential thermogravimetric analysis (DTG) were performed using a Pyris Diamond TG/DTA thermal analyzer (Perkin-Elmer, USA). Scanning electron microscopy (SEM) measurements were conducted on a cold field emission scanning electron microscope JSM6701F (JEOL, Japan).

\section{Results and discussion}

\subsection{RAFT polymerization of TE-AA in dioxane}

Homopolymerization of TE-AA by the RAFT process was perfomred with ACVA as an initiator and 3benzylsulfanylthiocarbonylsufanylpropionic acid as a chain transfer agent (CTA) under an N2 atmosphere. It is showed the time-conversion relationship between the homopolymerization of TE-AA and the pseudo-first order kinetic plot in dioxane in Figure 2. According to the 1H NMR spectroscopy, it could be performed to test the monomer consumption. Within $2 \mathrm{~h}$, a monomer conversion arrived at $53.1 \%$. The pseudo-first-order kinetic plot for the RAFT polymerization showed a deviated trend which has obvious difference from the first-order kinetics (Figure 2). From the downward curvature, we observed that the concentration of propagating radicals was decreasing[39]. Similar deviation has been reported for the RAFT polymerization of $\mathrm{N}$-acryloylmorpholine[40], N,Ndimethylacrylamide[41] and sodium 6acrylamidohexanoate[42] from the first-order kinetics.

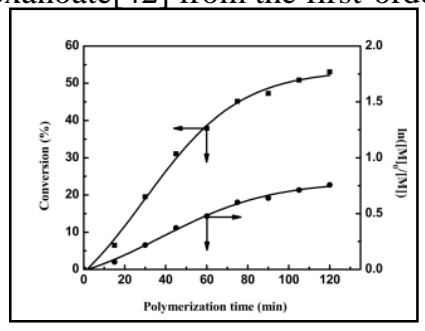

Figure 2. Time-conversion ( $\mathbf{a})$ and pseudo-first-order kinetic plots $(\bullet)$ for polymerization of TE-AA in the presence of RAFT agent in dioxane at $90^{\circ} \mathrm{C}$.

Figure 3 showed values of $\mathrm{Mn}$ and $\mathrm{Mw} / \mathrm{Mn}$ for RTE-PAA in the RAFT radical polymerization. The increase in $\mathrm{Mn}$ with conversion was linear, and the resulting polydispersity was narrow $(\mathrm{Mw} / \mathrm{Mn}=1.36)$.
There was the marked deviation of the GPC molecular weight from the theoretical number-average molecular weight $(\mathrm{Mn})$.

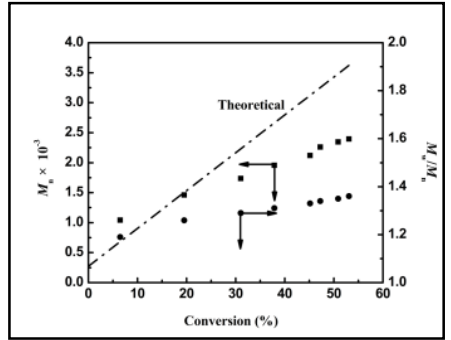

Figure 3. Dependence of $M_{\mathrm{n}}(\boldsymbol{\bullet})$ and $M_{\mathrm{w}} / M_{\mathrm{n}}(\bullet)$ on monomer conversion in the polymerization of TE-AA in dioxane at

$90{ }^{\circ} \mathrm{C}$. The broken line represents the theoretical line.

\subsection{Electrochemical polymerization of R-TE-PAA and TE-PAA}

The anodic polarization curves of R-TE-PAA and TEPAA were shown in Figure 4. To overcome the low solubility of the precursors in pure BFEE, the mixture of $50 \%$ (vol) BFEE and 50\% (vol) $\mathrm{CH} 2 \mathrm{Cl} 2$ was used in this work. The onset oxidation potential of R-TE-PAA (0.96 $\mathrm{V})$ was lower than that of TE-PAA $(0.99 \mathrm{~V})$, and clearly lower than that of thiophene $(1.35 \mathrm{~V}$ in the acetonitrile solution with $80 \%$ BFEE) [43], we can find that the onset oxidation potential of the precursor with broad PDI was higher than that of the precursor with narrow PDI from Figure 4.

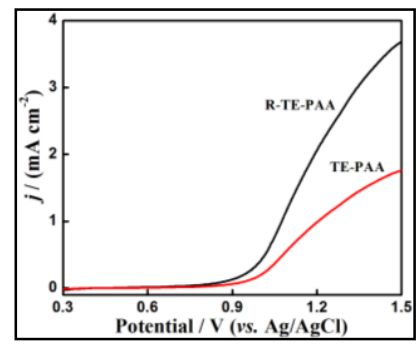

Figure 4. Anodic polarization curves of $6.5 \mathrm{mmol} / \mathrm{L} \mathrm{R}-\mathrm{TE}-$ PAA and TE-PAA in the electrolyte of $50 \% \mathrm{BFEE}+\mathrm{CH}_{2} \mathrm{Cl}_{2}$. Potential scan rate: $50 \mathrm{mV} / \mathrm{s}$.

The cyclic voltammetry can be applied to qualitatively reveal the reversibility of electron transfer during electrochemical polymerization and examine the electrical activity of polymer films by monitoring the oxidation and reduction in the form of a current-potential diagram[44, 45]. The successive cyclic voltammetrys $(\mathrm{CVs})$ of R-TE-PAA and TE-PAA in the electrolyte of $50 \%$ (vol) BFEE and $50 \%$ (vol) $\mathrm{CH} 2 \mathrm{Cl} 2$ on a $\mathrm{Pt}$ electrode were recorded. As shown in Figure 5, the CVs of both R-TE-PAA and TE-PAA exhibited characteristic features of conducting polymers during potentiodynamic syntheses, such as polythiophene[46] and polypyrrole[47]. The increasing redox peak current density on each $\mathrm{CV}$ indicated the gradually growing of R-PTE-PAA and PTE-PAA films. Upon repeated scanning, a broad reversible redox process was developed at 0.84 and $0.18 \mathrm{~V}$ for R-TE-PAA, and at 0.90 
and $0.28 \mathrm{~V}$ for TE-PAA, suggesting the formation of an electroactive polymers with good redox reversibility. From the neutral state to the metallic state, the broad distribution of the polymer chain length or the conversion of conductive species on polymer main chain might ascribe to the wide redox waves of as-formed films[48]. At the same time, it can be seen that the color of both polymer films electrodeposited on the working electrode during $\mathrm{CV}$ proceeding were converted from blue-green to dark blue. With the CV scanning going on, a apparent shift was maintaining from the redox waves on account of increasing electrical resistance, resulting to the over potential needs[49].

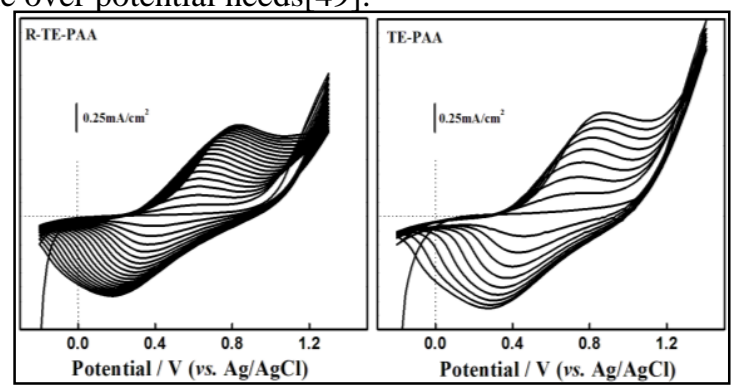

Figure 5. Cyclic voltammograms of $6.5 \mathrm{mmol} / \mathrm{L}$ R-TE-PAA and TE-PAA in $50 \% \mathrm{BFEE}+\mathrm{CH}_{2} \mathrm{Cl}_{2}$. Potential scan rate: 150 $\mathrm{mV} / \mathrm{s}$.

\subsection{Electrochemistry of R-PTE-PAA and PTE- PAA films}

The electrochemical behaviors of as-prepared films were studied under different potential scanning rates in monomer-free $50 \% \mathrm{BFEE}$ and $50 \% \mathrm{CH} 2 \mathrm{Cl} 2$. The steady-state $\mathrm{CVs}$ represented broad anodic and cathodic peaks (Figure 6), which were similar to the results in the literature[50]. The proportional relation between the peak current densities the potential scan rates (the insert of Figure 6) suggested that diffusion limits had no effect on the redox processes and the electroactive materials were stick to the working electrode surface[51]. Meanwhile, during the repeated cycle redox processes, there was no significant decomposition, which indicated that both films had high structural and electrochemical stability. The current peak values of polymer films at the potential scan rate of $150 \mathrm{mV} \mathrm{s}-1$ were listed in Table 1 . As reported previously[52], if the peak separation $(\Delta \mathrm{E}=$ Ep,a - Ep,c, Ep,a and Ep,c, anodic and cathodic peak potentials, respectively) was lower and the jp,c / jp,a (jp,a and jp,c, the current densities of anodic and cathodic peaks, respectively) ratio of the polymer film was larger, the redox behavior of the polymer film was more reversible. Therefore, it can be seen from Table 1 that the resultant polymer from precursor R-TE-PAA had better electrochemical reversibility than that from precursor TE-PAA.

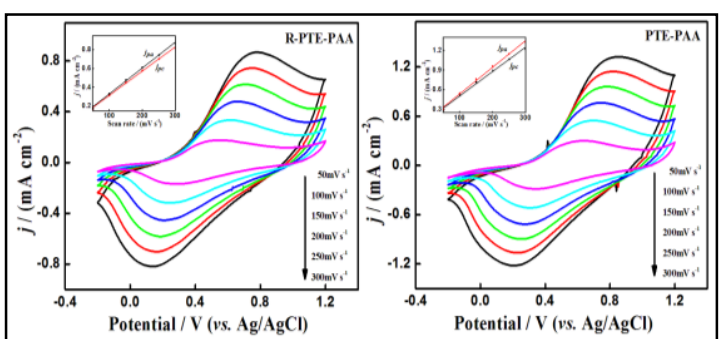

Figure 6. Cyclic voltammograms of R-PTE-PAA and PTE$\mathrm{PAA}$ in $50 \% \mathrm{BFEE}+\mathrm{CH}_{2} \mathrm{Cl}_{2}$. Inset: plots of redox peak current densities $v s$. potential scan rates. $j_{\mathrm{p}}$ is the peak current density: $j_{\mathrm{p}, \mathrm{a}}$ and $j_{\mathrm{p}, \mathrm{c}}$ denote the anodic and cathodic peak current densities, respectively.

Table 1. Redox peak values of polymers prepared in $50 \%$ $\mathrm{BFEE}+\mathrm{CH}_{2} \mathrm{Cl}_{2}$ (Potential scan rate: $150 \mathrm{mV} / \mathrm{s}$ )

\begin{tabular}{ccccccc}
\hline & $\begin{array}{c}E_{\mathrm{p}, \mathrm{a}} \\
(\mathrm{V})\end{array}$ & $\begin{array}{c}E_{\mathrm{p}, \mathrm{c}} \\
(\mathrm{V})\end{array}$ & $\Delta E / \mathrm{V}$ & $\begin{array}{c}j_{\mathrm{p}, \mathrm{a}}(\mathrm{mA} \\
\left.\mathrm{cm}^{-2}\right)\end{array}$ & $\begin{array}{c}j_{\mathrm{j}, \mathrm{c}}(\mathrm{mA} \\
\left.\mathrm{cm}^{-2}\right)\end{array}$ & $j_{\mathrm{p}, \mathrm{c} /} j_{\mathrm{p}, \mathrm{a}}$ \\
\hline $\begin{array}{c}\text { R-PTE- } \\
\text { PAA }\end{array}$ & 0.64 & 0.21 & 0.43 & 0.48 & 0.45 & 0.95 \\
$\begin{array}{c}\text { PTE- } \\
\text { PAA }\end{array}$ & 0.76 & 0.28 & 0.48 & 0.76 & 0.71 & 0.94 \\
\hline
\end{tabular}

Good electrochemical stability of conducting polymer films is commonly considered as a pivotal parameter for their applications[3]. Hence, the long-time cyclic voltammetry method was selected to test the electrochemical stability of the polymers under ambient conditions at the potential scan rate of $150 \mathrm{mV} \mathrm{s}-1$ and the result was shown in Figure 7. The corresponding parameters of the electrochemical stability of polymers were summarized in Table 2. It can be seen that both polymer films exhibited outstanding stability, suggesting great potential of applications in different fields, such as electrochromics, supercapacitors, electrochemical (bio) sensors, etc. Meanwhile, after 3000 cycles, the retentions of R-PTE-PAA and PTE-PAA were $60.29 \%$ and $51.00 \%$ respectively, which showed R-PTE-PAA had more electrochemical stability than PTE-PAA.

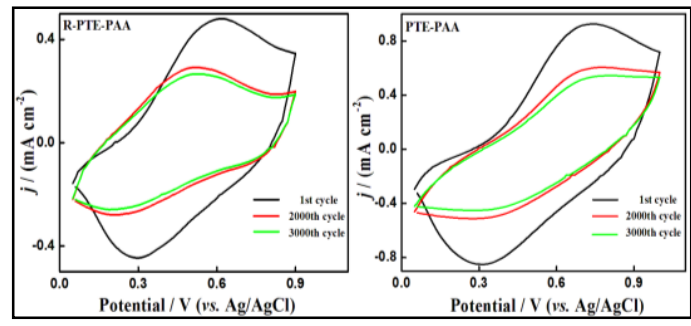

Figure 7. Cyclic voltammograms of R-PTE-PAA and PTE$\mathrm{PAA}$ in $50 \% \mathrm{BFEE}+\mathrm{CH}_{2} \mathrm{Cl}_{2}$ upon repeated cycling at the scan rate of $150 \mathrm{mV} / \mathrm{s}$.

Table 2. The parameters of the electrochemical stability for polymers.

\begin{tabular}{ccc}
\hline \multirow{2}{*}{ Cycle } & R-PTE-PAA & PTE-PAA \\
\cline { 2 - 3 } & Stability (\%) & Stability (\%) \\
\hline $1^{\text {st }}$ & 100 & 100 \\
$1000^{\text {th }}$ & 75.14 & - \\
\hline
\end{tabular}




\begin{tabular}{lcc}
\hline $2000^{\text {th }}$ & 66.28 & 58.97 \\
$3000^{\text {th }}$ & 60.29 & 51.00 \\
$5000^{\text {th }}$ & 55.87 & - \\
\hline
\end{tabular}

\subsection{Electrochromic properties of R-PTE-PAA and PTE-PAA Films}

Electrochemical redox can be presented via electrochromism which is considered as a reversible and visible change in the transmittance or reflectance of a material[53]. The redox processes of conjugated electroactive polymers couple with electrochromic phenomenous, resulting from ion insertion/expulsion[54]. Therefore, the electrochromic properties of the R-PTEPAA and PTE-PAA films were performed in 50\% BFEE $+\mathrm{CH}_{2} \mathrm{Cl}_{2}$, as the potential was stepped from the neutral to the doped state of the polymer. The color of the RPTE-PAA and PTE-PAA films switched from transparent yellow-green $(-0.2 \mathrm{~V})$ in the neutral state to dark blue in the doped state $(1.2 \mathrm{~V})$ (inserts of Figure 8$)$. It indicated that the R-PTE-PAA and PTE-PAA were electrochromic polymers materials.

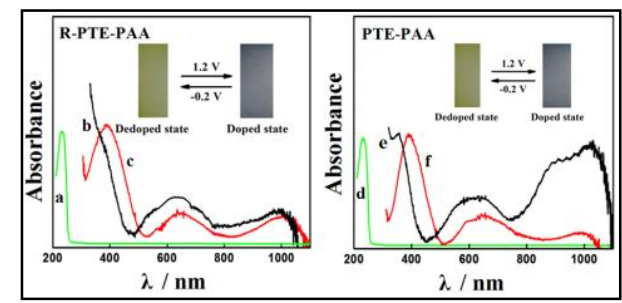

Figure 8. UV-Vis spectra of R-TE-PAA (a), doped (b) and dedoped (c) R-PTE-PAA, TE-PAA (d), doped (e) and dedoped (f) PTE-PAA. Insert: the electrochromism of RPTE-PAA and PTE-PAA films.

\subsection{Optical properties of R-PTE-PAA and PTE- PAA films}

The UV-vis spectra of doped and dedoped R-PTE-PAA and PTE-PAA films coated on an optically transparent ITO electrode as well as R-TE-PAA and TE-PAA precursors in THF were shown in Figure 8. The R-TEPAA and TE-PAA precursors in THF showed the similar absorption with a peak at 231-232 nm (Figure 9a\&d). Generally, absorption at longer wavelength in the spectra usually indicates higher conjugation length[55]. The valence band-conduction band $\left(\pi \sim \pi^{*}\right)$ transition of doped R-PTE-PAA (Figure 8b) was shifted to $350 \mathrm{~nm}$, which suggested that the conjugated chain had been extended. The peaks at 484-774 $\mathrm{nm}$ belonged to conductive species such as polaron or bipolaron. Moreover, the dedoped R-PTE-PAA (Figure 8c) presented absorption peaks at $387 \mathrm{~nm}$ and $529-803 \mathrm{~nm}$. For the doped and dedoped PTE-PAA, the valence bandconduction band $\left(\pi \sim \pi^{*}\right)$ transitions were at $356 \mathrm{~nm}$ (Figure 8e) and $388 \mathrm{~nm}$ (Figure 8f), respectively, which showed small red shift relative to those of doped and dedoped R-PTE-PAA. This implied that R-PTE-PAA and PTE-PAA had somewhat different conjugated chain length.

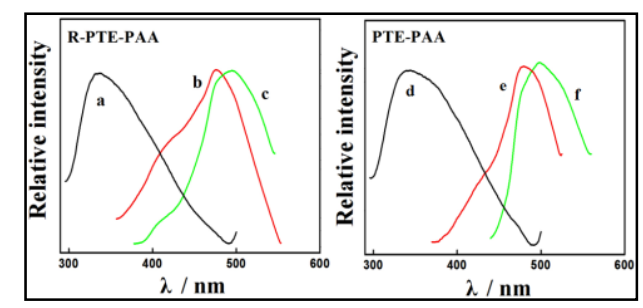

Figure 9. Fluorescence spectra of R-TE-PAA (a) in THF, doped (b) and dedoped (c) R-PTE-PAA in solid state, TEPAA (d) in THF, doped (e) and dedoped (f) PTE-PAA in solid state.

The fluorescence spectra of R-TE-PAA and TE-PAA precursors in THF and the corresponding doped and dedoped polymers in solid state were shown in Figure 9. The emission peak of R-TE-PAA emerged at $338 \mathrm{~nm}$ (Figure 9a), similar to that for TE-PAA (339 nm) (Figure 9d). The spectra of R-PTE-PAA film showed an emission peak at $476 \mathrm{~nm}$ with a shoulder peak from 375 to $435 \mathrm{~nm}$ in the doped state (Figure 9b), and a broad peak from 494 in the dedoped state (Figure 9c), displaying a clear red shift. The broadening and red shift of peaks can be ascribed to the wide molar mass distribution and long effective conjugation[56], in well agreement with the UV-Vis spectra. For the doped and dedoped PTE-PAA (Figure 9e \& f), the peaks were at 480 and $499 \mathrm{~nm}$, respectively. Data above demonstrated that as-prepared R-PTE-PAA and PTE-PAA polymers were good blue-light emitters.

\subsection{Structural characterization}

Figure 10 shows FT-IR spectra of R-TE-PAA and RPTE-PAA. In Figure 10, the peak at $3109 \mathrm{~cm}-1$ for R-TEPAA was attributed to the $\mathrm{C}-\mathrm{H}$ vibration of the 2, 5positions in the thiophene ring, which was not observed in the IR spectrum of R-PTE-PAA, indicating that the electropolymerization of R-TE-PAA took place at the 2,5-positions of the thiophene ring. The $\mathrm{C}=\mathrm{O}$ vibration frequency for the ester group appeared as a large peak at $1726 \mathrm{~cm}^{-1}$ in both of R-TE-PAA and R-PTE-PAA, with no change in intensity or wavelength, meaning that the PAA chains did not change during the electropolymerization process. On the other hand, as can be seen from Figure 10, the absorption bands of R-PTEPAA were obviously broadened compared with those of R-TE-PAA. Similar phenomenon was also observed in other conducting polymers[57]. This was mainly due to the wide chain dispersity of the resulting product composed of oligomers/polymers[44]. In more details, the vibration modes of the polymers with different polymerization degrees showed different IR shifts. These peaks overlapped one another and produced broad bands with hyperstructures. Furthermore, the chemical defects on the polymer chains resulting from the overoxidation of the polymer and $\alpha-\beta, \beta-\beta$ connections also contributed to the band broadening of IR spectra[58]. 


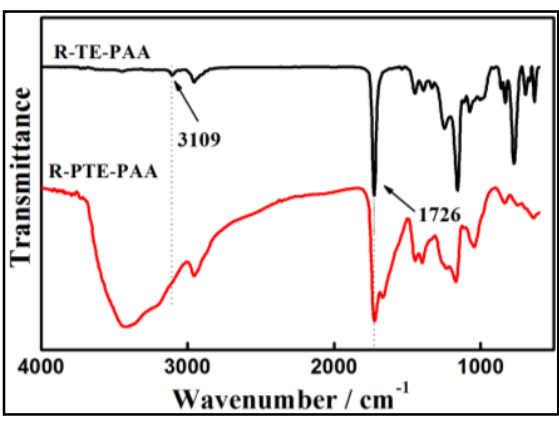

Figure 10. FT-IR spectra of R-TE-PAA and R-PTE-PAA.

\subsection{Thermal properties of R-PTE-PAA and PTE- PAA films}

Thermal stability is a very important factor for the applications of a polymer. Figure 11 gives the TG and DTG curves of R-PTE-PAA and PTE-PAA films under a nitrogen stream with a heating rate of $10 \mathrm{~K} \mathrm{~min}^{-1}$. The degradation of each polymer can be divided into two steps according to the two peaks in the DTG curve of each polymer. The polymer initially underwent a small weight decrease about $5.3 \%$ at relatively low temperature range from 300 to $373 \mathrm{~K}$, which may be attributed to the moisture evaporation and a few oligomers trapped in the polymer[59-62], which was not necessarily associated with a change in polymer structure. With the gradual increasing temperature, a prominent weight loss step about $42.33 \%$ was clearly found at $516 \mathrm{~K}<\mathrm{T}<765 \mathrm{~K}$, which was essentially due to the oxidizing decomposition of the skeletal PTE and/or PAA backbone chain structures. It started to lose weight prominently when the temperature reached $450 \mathrm{~K}$ and up to $52.24 \%$ decomposition when the temperature reached $852 \mathrm{~K}$, PTE-PAA films showed better thermal stability with only $44.65 \%$ losses when the temperature reached $852 \mathrm{~K}$. It was because that more intercoupling reaction between macromolecule radicals often emerging during the progress of free radical polymerization maybe lead to the generation of crosslinked polymerization.

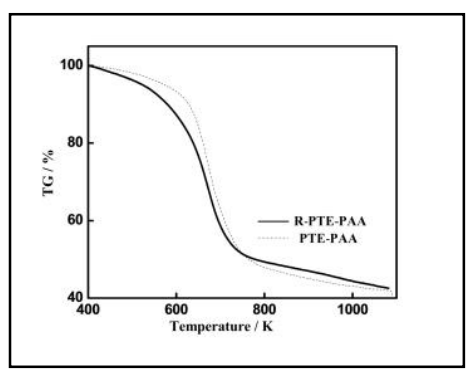

Figure 11. TG curves of dedoped R-PTE-PAA and PTE-PAA films.

\subsection{Morphologies of R-PTE-PAA and PTE-PAA films}

To get their surface morphology, the doped and dedoped R-PTE-PAA and PTE-PAA films deposited on the ITO electrode were investigated (Figure 12). As can be seen from Figure 12A, doped R-PTE-PAA film was presented in the form of tumer-like aggregations. After dedoping, the surface of dedoped R-PTE-PAA film showed some defects or flaws to some extent (Figure 12B). This was due to the leaving of doping anions in R-TE-PAA film during the process of electrochemical dedoping. For the doped and dedoped PTE-PAA (Figure 12C\&D), the surfaces were smooth and homogeneous.

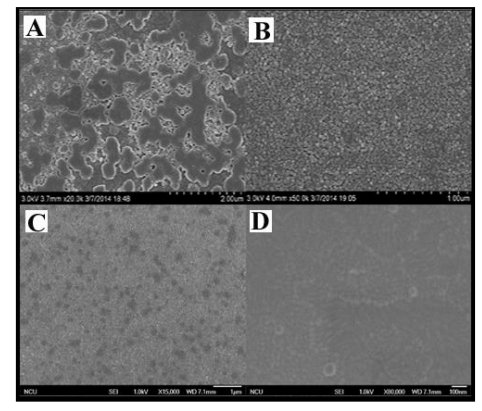

Figure 12. SEM photographs of doped (A) and dedoped (B) R-PTE-PAA films and doped (C) and dedoped (D) PTE-PAA films deposited electrochemically on ITO electrode.

\section{Conclusions}

In summary, R-TE-PAA precursor with narrow PDI was prepared via RAFT polymerization and subsequently electrodeposited into a free-standing crosslinked network R-PTE-PAA film in 50\% BFEE + DCM electrolyte. Asprepared R-PTE-PAA had good redox activity and electrochemical stability after 3000 cycles. Compared with precursor TE-PAA with broad PDI and its corresponding PTE-PAA polymer, R-TE-PAA precursor showed lower onset oxidation potential and R-PTE-PAA exhibited an enhanced electrochemical stability and thermal stability. In addition, R-PTE-PAA film with electrochromic property was a good blue emitter. These results indicated that the high stable electroactive materials may be applied in various fields, such as electrochromics, supercapacitors, electrochemical (bio)sensors. Therefore, RAFT polymerization is a novel and favorable method to prepare the precursors bearing electroactive aromatic ring units. Future work about block, star and comb precursors with heterocycles prepared by RAFT method will be continued.

\section{Acknowledgement}

This work was supported by the National Key Research and Development Program of China (2017YFD0800700), the Science and Technology Research fund of Guangdong, China (2016B020242006, 2016A020209005, and 2016TX03Z086), the Science and Technology Research fund of Guangzhou, China (201704020200 and 201710010128), the Research Foundation of Shanghai Institute of Technology (XTCX2015-15), the National Natural Science Foundation of China (No. 41171250), the Scientific Platform and Innovation Capability Construction Program of GDAS (2017GDASCX-0406 and 2017GDASCX-0834). 


\section{References}

1. S. Alkan, C. A. Cutler, J. R. Reynolds, Adv. Funct. Mater 13, 331 (2003)

2. M. R. Andersson, M. Berggren, O. Inganäs, G. Gustafsson, J. Gustafsson-Carlberg, D. Selse, T. Hjertberg, O. Wennerström, Macromolecules 28, 7525 (1995)

3. P. Bäuerle, S. Scheib, Adv. Mater 5, 848 (1993)

4. S. Barik, S. Valiyaveettil, Macromolecules 41, 6376 (2008)

5. M. Baum, W. J. Brittain, Macromolecules 35, 610 (2002)

6. M. Berggren, G. Gustafsson, O. Inganäs, M. R. Andersson, O. Wennerström, T. Hjertberg, Adv. Mater 6, 488 (1994)

7. M. Chen, M. Häussler, G. Moad, E. Rizzardo, Org. Biomol. Chem 9, 6111 (2011)

8. J. Chiefari, Y. Chong, F. Ercole, J. Krstina, J. Jeffery, T. P. Le, R. T. Mayadunne, G. F. Meijs, C. L. Moad, G. Moad, Macromolecules 31, 5559 (1998)

9. F. D'Agosto, R. Hughes, M.-T. Charreyre, C. Pichot, R. G. Gilbert, Macromolecules 36, 621 (2003)

10. M. S. Donovan, T. A. Sanford, A. B. Lowe, B. S. Sumerlin, Y. Mitsukami, C. L. McCormick, Macromolecules 35, 4570 (2002)

11. S. C. Farmer, T. E. Patten, J. Polym. Sci., Part A: Polym. Chem 40, 555 (2002)

12. M. L. Hallensleben, F. Hollwedel, D. Stanke, Macromol. Chem. Phys 196, 3535 (1995)

13. C. J. Hawker, A. W. Bosman, E. Harth, Chem. Rev 101, 3661 (2001)

14. A. Hogervorst, T. Kock, B. De Ruiter, A. van der Waal, Synth. Met 55, 1644 (1993)

15. F. Jonas, U. Guntermann, K. Lerch, A. Bohnke, H. Basten, P. Thometzek (1998)

16. F. Jonas, A. Karbach, B. Muys, E. van Thillo, R. Wehrmann, A. Elschner, R. Dujardin (2000)

17. D. E. Labaye, C. Jérôme, V. Geskin, P. Louette, R. Lazzaroni, L. Martinot, R. Jérôme, Langmuir 18, 5222 (2002)

18. E. Lankinen, G. Sundholm, P. Talonen, H. Granö, F. Sundholm, J. Electroanal. Chem 460, 176 (1999)

19. J. Levell, S. Zhang, W.-Y. Lai, S.-C. Lo, P. Burn, I. Samuel, Opt. Express 20, A213 (2012)

20. X.-G. Li, M.-R. Huang, W. Duan, Y.-L. Yang, Chem. Rev 102, 2925 (2002)

21. X. Li, Y. Li, J. Appl. Polym. Sci 90, 940 (2003)

22. X. Li, Y. Zhao, H. Li, X. Yuan, Appl. Surf. Sci 316, 222 (2014)

23. Y. Li, C. Chen, S. Zhang, Y. Ni, J. Huang, Appl. Surf. Sci 254, 5766 (2008)

24. J. Lowe, S. Holdcroft, Macromolecules 28, 4608 (1995)
25. B. Lu, C. Liu, Y. Li, J. Xu, G. Liu, Synth. Met 161, 188 (2011)

26. B. Lu, J. Yan, J. Xu, S. Zhou, X. Hu, Macromolecules 43, 4599 (2010)

27. N. A. Lynd, A. J. Meuler, M. A. Hillmyer, Progress in Polymer Science 33, 875 (2008)

28. K. Matyjaszewski, J. Xia, Chem. Rev 101, 2921 (2001)

29. H. Meng, D. F. Perepichka, M. Bendikov, F. Wudl, G. Z. Pan, W. Yu, W. Dong, S. Brown, J. Amer. Chem. Soc 125, 15151 (2003)

30. Y. Mitsukami, M. S. Donovan, A. B. Lowe, C. L. McCormick, Macromolecules 34, 2248 (2001)

31. G. Nie, J. Xu, S. Zhang, T. Cai, X. Han, J. Appl. Polym. Sci 102, 1877 (2006)

32. G. Nie, L. Zhou, H. Yang, J. Mater. Chem 21, 13873 (2011)

33. D. L. Patton, M. Mullings, T. Fulghum, R. C. Advincula, Macromolecules 38, 8597 (2005)

34. S. W. Prescott, M. J. Ballard, E. Rizzardo, R. G. Gilbert, Macromolecules 35, 5417 (2002)

35. L. Qin, J. Xu, B. Lu, Y. Lu, X. Duan, G. Nie, J. Mater. Chem 22, 18345 (2012)

36. J. F. Quinn, L. Barner, E. Rizzardo, T. P. Davis, J. Polym. Sci., Part A: Polym. Chem 40, 19 (2002)

37. N. Ranieri, G. Ruggeri, F. Ciardelli, Polym. Int 48, 1091 (1999)

38. R. Rodríguez, C. de Las Heras Alarcón, P. Ekanayake, P. J. McDonald, J. L. Keddie, M. J. Barandiaran, J. M. Asua, Macromolecules 41, 8537 (2008)

39. G. Sönmez, I. Schwendeman, P. Schottland, K. Zong, J. R. Reynolds, Macromolecules 36, 639 (2003)

40. H. T. Santoso, V. Singh, K. Kalaitzidou, B. A. Cola, ACS applied materials \& interfaces 4, 1697 (2012)

41. B. Senthilkumar, P. Thenamirtham, R. K. Selvan, Appl. Surf. Sci 257, 9063 (2011)

42. F. Stoffelbach, L. Tibiletti, J. Rieger, B. Charleux, Macromolecules 41, 7850 (2008)

43. A. Suzuki, D. Nagai, B. Ochiai, T. Endo, J. Polym. Sci., Part A: Polym. Chem 43, 5498 (2005)

44. J. Thieblemont, A. Brun, J. Marty, M. Planche, P. Calo, Polymer 36, 1605 (1995)

45. B. C. Thompson, P. Schottland, K. Zong, J. R. Reynolds, Chem. Mater 12, 1563 (2000)

46. Y. Tsujii, M. Ejaz, K. Sato, A. Goto, T. Fukuda, Macromolecules 34, 8872 (2001)

47. M. M. Verghese, M. Ram, H. Vardhan, B. Malhotra, S. Ashraf, Polymer 38, 1625 (1997)

48. C. Wang, X. Xie, E. LeGoff, J. Albritton-Thomas, C. R. Kannewurf, M. G. Kanatzidis, Synth. Met 74, 71 (1995)

49. J. Wang, B. Lu, C. Liu, J. Xu, M. Pei, J. Mater. Sci 45, 5769 (2010) 
50. T. Wang, C. de las Heras Alarcón, M. Goikoetxea, I. Beristain, M. Paulis, M. J. Barandiaran, J. M. Asua, J. L. Keddie, Langmuir 26, 14323 (2010)

51. X. Wang, Y. Luo, B. Li, S. Zhu, Macromolecules 42, 6414 (2009)

52. J.-k. Xu, W.-q. Zhou, J. Hou, S.-z. Pu, J.-w. Wang, L.-s. Yan, Chin. J. Polym. Sci 24, 47 (2006)

53. J. Xu, Z. Wei, Y. Du, W. Zhou, S. Pu, Electrochim. Acta 51, 4771 (2006)

54. A. Ylikantola, J. Linnanto, J. Knuutinen, A. Oravilahti, M. Toivakka, Appl. Surf. Sci 276, 43 (2013)

55. R. Yue, B. Lu, J. Xu, S. Chen, C. Liu, Polym. J 43, $531(2011)$

56. S.-i. Yusa, K. Fukuda, T. Yamamoto, K. Ishihara, Y. Morishima, BioMacromolecules 6, 663 (2005)

57. S.-i. Yusa, Y. Shimada, Y. Mitsukami, T. Yamamoto, Y. Morishima, Macromolecules 36, 4208 (2003)

58. P. B. Zetterlund, Y. Kagawa, M. Okubo, Chem. Rev 108, 3747 (2008)

59. B. Zhang, B. Liu, X. Deng, S. Cao, X. Hou, H. Chen, Appl. Surf. Sci 254, 452 (2007)

60. M. Zhou, J. Heinze, J. Phys. Chem B 103, 8451 (1999)

61. M. Zhou, J. Heinze, Electrochim. Acta 44, 1733 (1999)

62. W.-q. Zhou, J.-k. Xu, Z.-h. Wei, S.-z. Pu, Chin. J. Polym. Sci 26, 81 (2008) 